\title{
Estimation of Solar Energy Potential under Conditions of Urban Development
}

\author{
Daus Yuliia \\ Azov-Black Sea Engineering Institute \\ FSBEI HE «Don SAU» \\ Zernograd, Russian Federation \\ zirochka2505@gmail.com
}

\author{
Yudaev Igor \\ Azov-Black Sea Engineering Institute \\ FSBEI HE «Don SAU» \\ Zernograd, Russian Federation \\ etsh1965@mail.ru
}

\begin{abstract}
A large number of regions are attractive for the application of renewable energy equipment, including those that are using the solar energy potential. But the volatile nature of the solar radiation flux requires specific forecasts and calculations of its intensity. Besides, installations under urban conditions are widely used in two forms: solar power plants which photovoltaic panels are placed at a certain angle to the horizon on a flat building roof; and integrated photovoltaic panels in the building construction. However, the use of such power supply systems is limited by the structural features of the roofs of buildings. That is why, it is necessary to take into account the mutual shading of the rows of photovoltaic panels and by the structural elements. This leads to limitation of the capacity of the installation and to shortage of the utilization of the solar energy technical potential for the installation placement. Integrating photovoltaic panels into the building structure, a decrease in the amount of generated electric energy are associated with a deviation from their optimal spatial orientation, which leads to reduction in the coefficient of the used installed capacity of electrical equipment, that is, the low efficiency of conversion of solar energy into electrical energy. That is why, an accurate assessment of the solar potential of renewable energy sources, taking into account the design features of urban development, allows one to justify the parameters of the generating unit at a design stage, and to predict its operating mode and to evaluate technical and economic efficiency
\end{abstract}

Keywords - solar energy, tilt angle of the receiving surface, orientation by the sides of the world

\section{INTRODUCTION}

The application of systems of solar power supply allows using extensively local fuel-free energy sources; it reduces environmental pollution and operating costs. However, in power network there is change of such technical and economic parameters of the network as losses, electricity cost, voltage level and reliability. Thus to design an efficient power network it is necessary to solve a number of problems that are justification of the generation source parameters, search of connection location to the network, technical implementation of network connection, the economic substantiation of its parameters.

Parameters of generating installation based on renewable energy conversion depend on the selection of the voltage level, consumers' capacity and the primary energy source potential of the region, considering the technical, social, environmental and other restrictions. At the same time, both energy storage devices and the available spare capacity of Unified Energy System can be used to compensate the variable nature of the solar energy.

The ecological state of areas, especially around the big cities and large urban conglomerates, as well as an increasing anthropogenic load on the environment, is forcing to seek and promote clean and affordable sources of energy, which primarily include the aggregates of carbon-free energy. This energy of the future relies primarily on renewable energy sources, including solar energy.

To increase efficiency of functioning solar power plants is possible by maximizing utilization of the available solar energy potential. It is technically possible to implement without additional capital expenses by determining the optimum tilt angle of the receiving surface of photovoltaic panels relative to the horizon.

The power supply systems of cities and settlements are characterized by a high level of their centralization. These systems should provide high reliability and efficiency, which is determined by the need for uninterrupted power supply of urban consumers, with a specifically set and maintained quality of provided services [1]. The main energy consumers are large production structures, located in urban areas, as well as institutions of social orientation and the housing and communal sector. The organization of normal, trouble-free operation of production processes is ensured by uniform and continuous energy carriers with a predetermined quality, supplied to industrial facilities. At the same time, the continuity of the ongoing processes is ensured by the organization of electrical energy supply from several substations, and of thermal energy supply from several boiler houses. Such structure is not always applied for energy supply of social institutions and in the communal sector. Therefore, organizing the ensuring uninterrupted power supply, especially in case of accidents or preventive works on the elements of energy structures, additional energy supply, that is independent of the listed conditions, should be provided [2]

In the context of reducing budget expenditures [3], the introduction of renewable energy sources into the practice of energy supply is urgent for the communal needs of the social sector. However, owing to their diversity, not all designs of renewable energy sources can be applied in urban development. In the authors' opinion, they must be considered as the most effective universal source that could use primary 
renewable energy, be converted into both electric and thermal energy, which power equipment can be located and mounted on existing building structures. The existing generating units that operate using solar energy meet the majority of mentioned requirements.

A large number of regions are attractive for the application of renewable energy equipment, including those that are using the solar energy potential. But the volatile nature of the solar radiation flux requires specific forecasts and calculations of its intensity [4].

Besides, installations under urban conditions are widely used in two forms: the first one is solar power plants which photovoltaic panels are placed at a certain angle to the horizon on a flat building roof; and the second one is integrated photovoltaic panels in the building construction.

However, the use of such power supply systems is limited by the structural features of the roofs of buildings. For the first approach, it is necessary to take into account the mutual shading of the rows of photovoltaic panels and by the structural elements [5-7]. This leads to limitation of the capacity of the installation and to shortage of the utilization of the solar energy technical potential for the installation placement. Integrating photovoltaic panels into the building structure, a decrease in the amount of generated electric energy are associated with a deviation from their optimal spatial orientation, which leads to reduction in the coefficient of the used installed capacity of electrical equipment, that is, the low efficiency of solar energy converting into electrical energy [8].

That is why, an accurate assessment of the solar potential of renewable energy sources, taking into account the design features of urban development, allows one to justify the parameters of the generating unit at a design stage, and to predict its operating mode and to evaluate technical and economic efficiency.

\section{PURPOSE OF THE RESEARCH}

Assessment of the solar radiation level under urban conditions, used in the design, and justification of the introduction on urban territories of power plants that convert renewable solar energy are the purposes of the study.

\section{RESEARCH METHOD}

To estimate accurately the solar energy potential at a specific point in a particular area, it is necessary to know the hourly values of all the components of solar radiation reaching the earth's surface. Reliable assessment of the necessary solar insolation values for engineering calculations can be made using the developed technique, described in details in [9-10]. The calculation algorithm is described below. Using the method of applying the daily profile of solar radiation under absolutely clear sky, the authors calculated the monthly sums of direct and diffused solar radiation on horizontal surface for the node points of coordinate grid. Further, similar values are obtained as a result of actinometric measurements from the NASA database for real atmospheric conditions. At the next stage, the values of the adaptation coefficients of direct and diffused radiation for each month are calculated at the node points, and their identification is carried out by methods of separating variables and approximation, taking into account geographical coordinates. Further, the values of all components of solar radiation and the time period, by applying the daily profile of solar radiation under absolutely clear sky, taking into account the adaptation coefficients to real atmospheric conditions, are determined for the required latitude and longitude.

The US National Aeronautics and Space Administration created the SSE NASA meteorological database on the basis of a data array obtained as a result of the measurements of solar radiation characteristics by satellites and ground meteorological stations.

The algorithm of calculation for speed and convenience was put into the computer program, the dialog box of which is presented in Fig. 1.

The authors suggested entering the coordinates of the location of the solar power plant, as well as specifying the target value and form of display of the obtained results (a diagram and/or a text file), and then pressing the "Calculation" button. The time of calculation does not exceed 7-10 s.

The calculation error of the proposed computer program as compared to the real results of meteorological observations, does not exceed $5 \%$ by month and $3 \%$ for annual sums, which shows that it is sufficiently accurate.

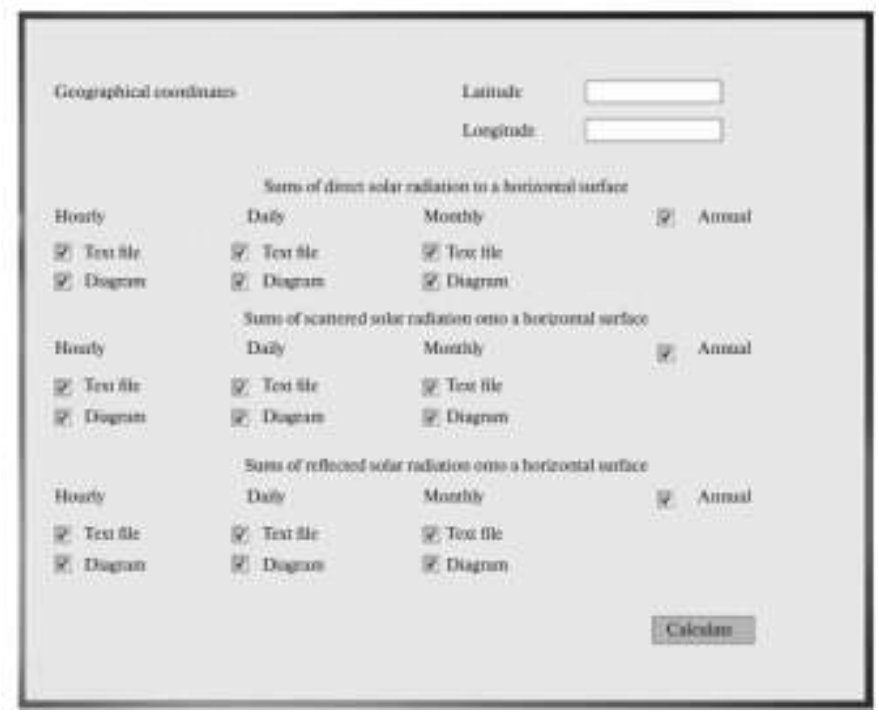

Fig. 1. Dialog box for calculating solar energy potential at given geographic point

The main initial data for the calculation are the geographical coordinates of the region or a specific location. For example, for the city of Volzhskiy of Volgograd Region there are: $48.78^{\circ} \mathrm{N}, 44.77^{\circ} \mathrm{E}$. 


\section{RESULTS AND THEIR DISCUSSION}

Solar power plants are most often connected to existing internal networks and communications at modernized or projected facility, being placed on roofs, the shape and the design of which can vary from flat to ramp with different inclination angles [10].

Flat roofs are the simplest for design decision as their shape repeats the surface of horizontally arranged heliofields and for which the design requirements have been developed quite extensively [11, 12]. Therefore, the configuration of roofs with sloping construction solutions has to be considered.

Calculation of the solar radiation intensity is carried out for the receiving surface, planned for placement at the optimal tilt angle of the gable roof [11] of $20-50^{\circ}$ with orientation to the East, South-East, South, South-West and West, according to the geographical coordinates of the city Volzhskiy. As the calculated tilt angle of the pitched roof, the value of $30^{\circ}$ was taken.

Fig. 2 presents the results of calculating the hourly sums of direct, diffused and reflected solar radiation using the proposed program.

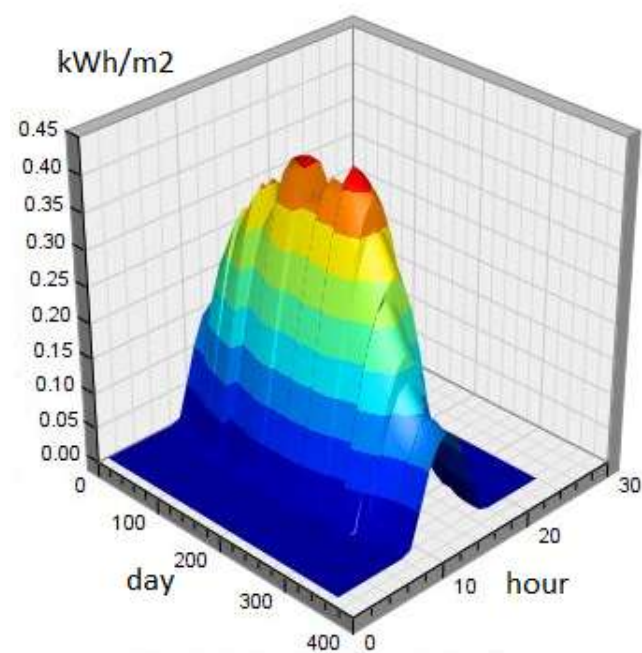

a)

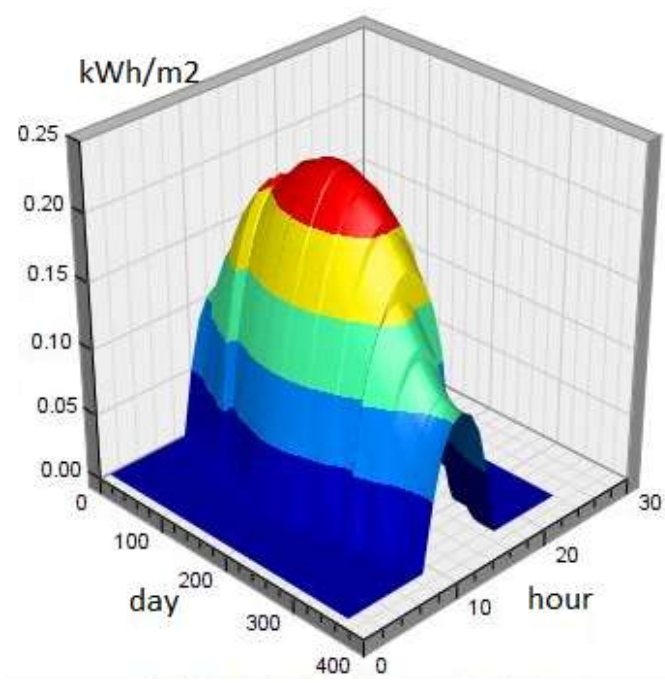

b)

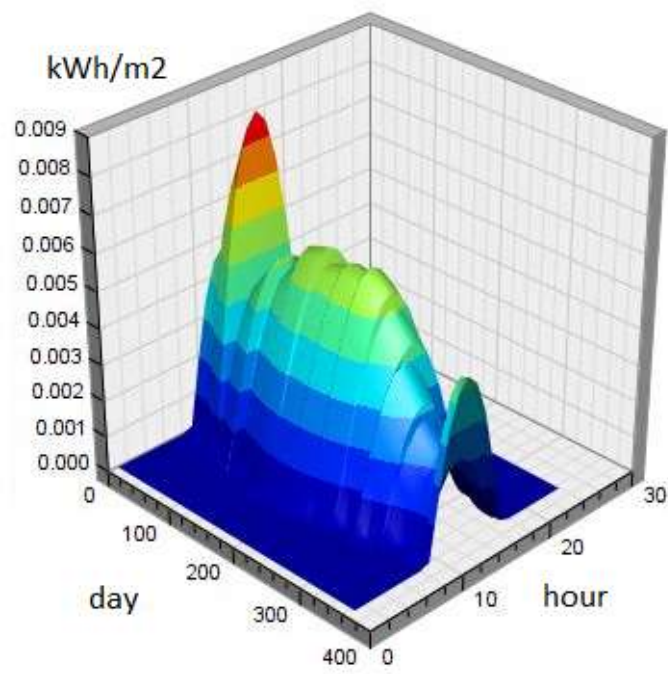

c)

Fig. 2. Hourly sums of direct (a), diffused (b) and reflected (c) components of solar radiation for given geographic coordinates of the southern orientation at the angle of $20^{\circ}$ to the horizon

The calculation results of the annual values of total insolation for differently oriented sites (roof slopes), with respect to both the horizon and the sides of the world, are presented in Fig. 3. 


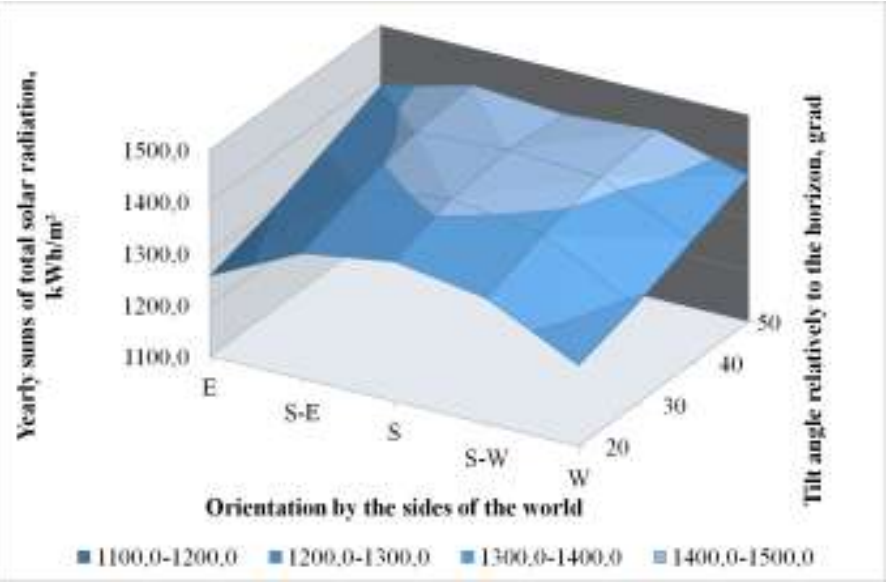

Fig. 3. Annual values of solar radiation coming on differently oriented surfaces

Under climatic conditions of the city Volzhskiy, the annual value of solar radiation coming on a horizontal surface is $1231.98 \mathrm{kWh} / \mathrm{m}^{2}$. It can be concluded from Fig.3 that the solar energy potential can be increased by different orientations of the PV panels in space. Thus, the energy flux reaches its maximum value in the South-East or South-West orientation at an inclination angle with respect to the horizon of $50^{\circ}$. At the value below $50^{\circ}$, southern orientation is the most favorable one. However, installing a solar power station on the building roof, the orientation along the sides of the world correspond to the orientation of the roof slope. Analysis of the values of the tilt angles relatively the horizon at such structural constraint revealed that when orientation of solar module is eastern or western, as well as the southeastern or southwestern, large values of the inclination angles relatively horizon have to be chosen. It is due to the fact that this spatial position is aimed at the utilization of solar radiation at the dawn and sunset time when the Sun is low above the horizon.

As preventive repairs of communal structures and energy transmission systems are seasonal, before designing solar power plants and selection of the inclination angle of their receiving surfaces, it is necessary to analyze the data, obtained on the basis of calculating sums of the total solar radiation intensity depending on the time of the year, to obtain maximum output from the incoming solar radiation intensity. Fig. 4 presents the calculated seasonal sums of the total solar radiation that is incident on the differently oriented receiving surfaces with a tilt angle of $30^{\circ}$.

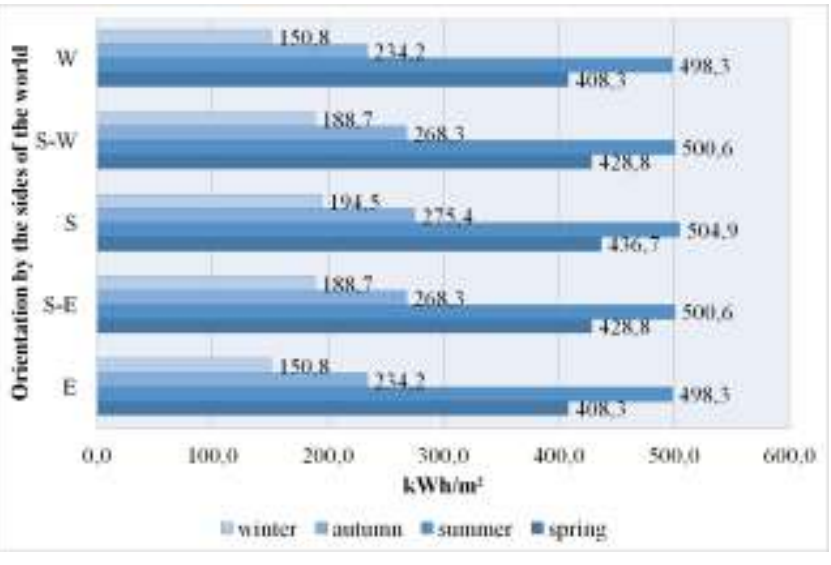

Fig. 4. The seasonal values of total insolation coming on the receiving surface at tilt angle of $30^{\circ}$ to the horizon with different orientations to the sides of the world

The analysis of the results that are presented in Fig. 5 reveals that the orientation to the south at the same inclination angle of the roof surface relatively the horizon should be considered as an optimal one. However, it is not always possible to use such building roofs for placing solar power plants on them. The calculation results also show that the deviation of the location from the South to the South-East or the South-West is characterized by a slight decrease in solar insolation. But the orientation to the West or East in comparison with the southern direction leads to decrease in the amount of incoming solar radiation, respectively, from $7 \%$ - in spring to $22 \%$ - in winter.

Choosing and completing the solar energy conversion system, one should know the proportion of incoming direct, diffused and reflected radiation. Such ratio of the solar radiation components, which reach the surface of the receiving area with a tilt angle of $30^{\circ}$ relatively the horizon and orientation to the South-East (South-West), taking into account the specific season for Volzhskiy, is presented in Fig. 5 .

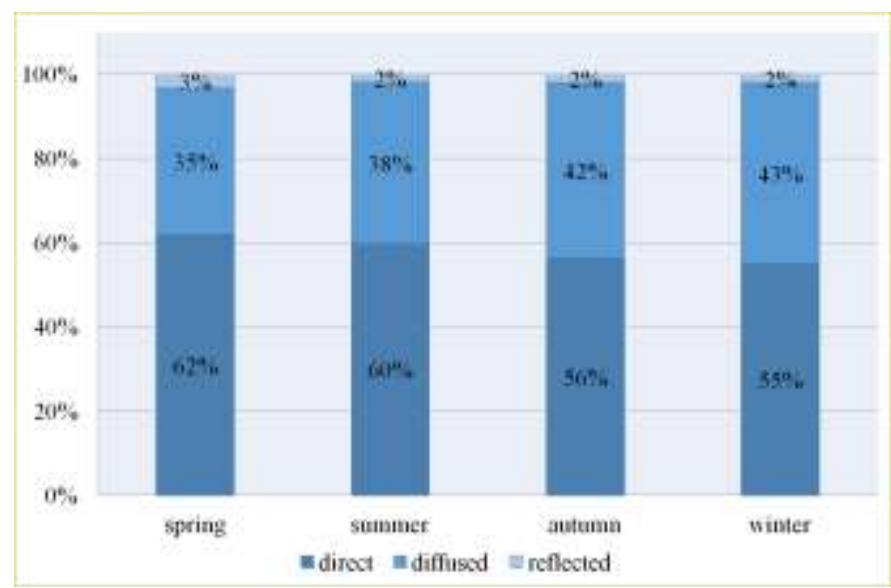

Fig. 5. The components of total solar radiation, coming on inclined surfaces

As one sees from Fig. 6, the diffused component ranges from $35 \%$ to $43 \%$ in different seasons, so it can not be neglected. According to the calculation formulas [9], its value 
depends on the inclination angle of the receiving surface with respect to the horizon, which imposes additional restrictions on the choice of the tilt angle of the roof slope, if the solar power supply is envisaged even at the stage of designing buildings or constructing solar power installations located on horizontal structures .

Fig. 6-7 present data on the solar radiation intensity on differently oriented surfaces for the summer period in the city of Volzhskiy.

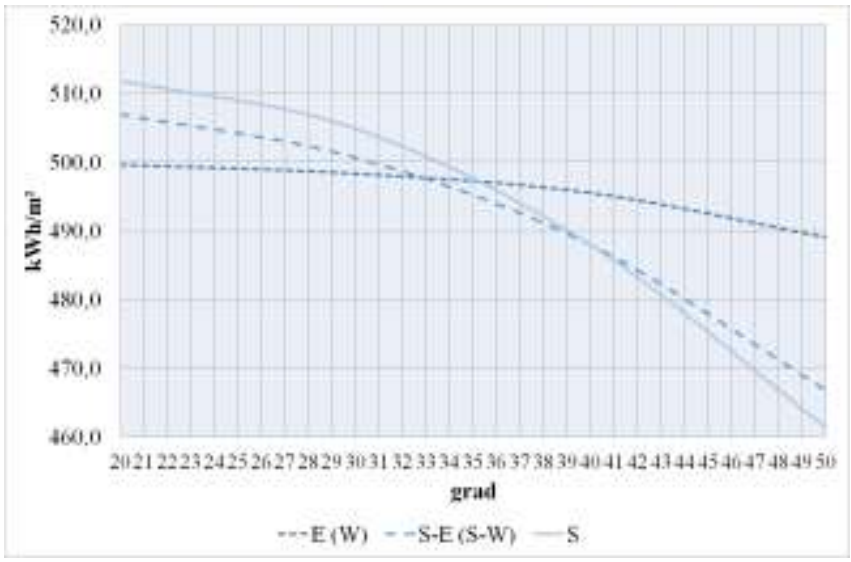

Fig. 6. Dependence of sums of solar radiation coming on receiving surface on surface's orientation to sides of the world for summer period

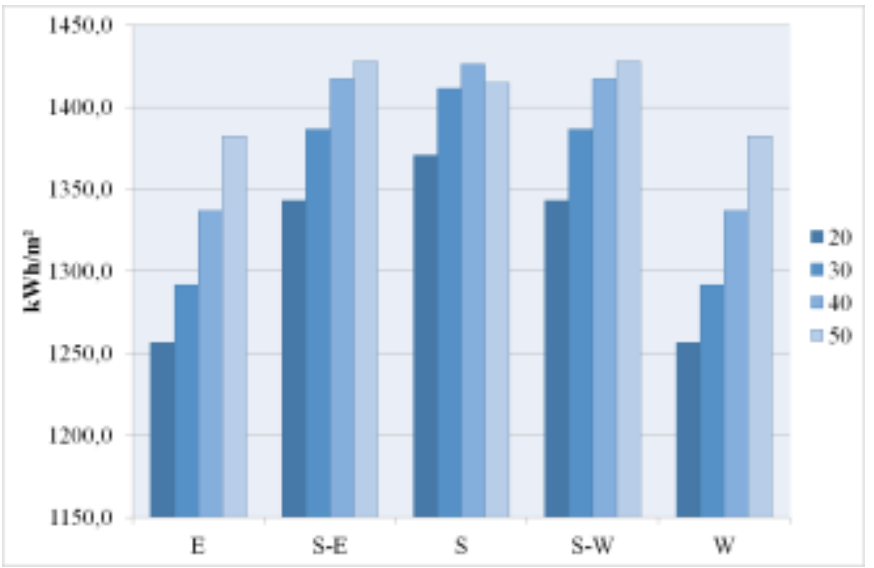

Fig. 7. The annual sums of solar radiation coming on the receiving surface of different spatial orientations at certain inclination angles relatively the horizon

One can note that the maximum and minimum values of the total radiation were detected for the southern orientation, respectively, at $20^{\circ}$ and $50^{\circ}$ relatively the horizon. So, at the eastern orientation, the radiation intensity decreases with an increase in the inclination angle of the receiving platform from $499.6 \mathrm{kWh} / \mathrm{m}^{2}$ to $489.1 \mathrm{kWh} / \mathrm{m}^{2}$.

The authors can conclude that for the given orientation to the sides of the world, it is preferable to choose smaller tilt angles of the roof slope. So, for example, when orientation is southern, it is desirable to use the inclination angles of the surface of up to $41^{\circ}$, but for the western orientation, the choice of the angle relatively the horizon does not significantly affect the amount of received solar energy.
Besides, at the inclination angle of the receiving surface of $20^{\circ}-35^{\circ}$, the southern direction can be recommended, and for angles that are bigger than $35^{\circ}$, the eastern (western) orientation should be considered as the best one. If it is impossible to provide such solution constructively, then at an inclination angle relatively the horizon of above $41^{\circ}$, it is rational to plan and locate receiving surfaces of power plants oriented to the South-East (South-West).

\section{CONCLUSION.}

Despite the fact that a large number of regions are attractive for the application of renewable energy equipment, including those that are using the solar energy potential. The volatile nature of the solar radiation flux requires specific forecasts and calculations of its intensity. Besides, installations under urban conditions are widely used in two forms: solar power plants which photovoltaic panels are placed at a certain angle to the horizon on a flat building roof; and integrated photovoltaic panels in the building construction. However, the use of such power supply systems is limited by the structural features of the roofs of buildings. That is why, it is necessary to take into account the mutual shading of the rows of photovoltaic panels by the structural elements. This leads to limitation of the capacity of the installation and to shortage of the utilization of the solar energy technical potential for the installation placement. Integrating photovoltaic panels into the building structure, a decrease in the amount of generated electric energy are associated with a deviation from their optimal spatial orientation, which leads to reduction in the coefficient of the used installed capacity of electrical equipment, that is, the low efficiency of converting solar energy into electrical energy. That is why, an accurate assessment of the solar potential of renewable energy sources, taking into account the design features of urban development, allows one to justify the parameters of the generating unit at a design stage, and to predict its operating mode and to evaluate technical and economic efficiency.

Solar power plants are most often connected to existing internal networks and communications at a modernized or projected facility, being placed on roofs, the shape and design of which can vary from flat to ramp with different inclination angles.

Flat roofs are the simplest for design decision as their shape repeats the surface of horizontally arranged heliofields, and for which the design requirements have been developed quite extensively. Therefore, the configuration of roofs with sloping construction solutions that are widely used has to be analyzed.

Calculation of the solar radiation intensity is carried out for the receiving surface, planned for placement at the optimal tilt angle of the gable roof of $20-50^{\circ}$ with orientation to the East, South-East, South, South-West and West, according to the geographical coordinates of Volzhskiy. So the calculated tilt angle of the pitched roof is $30^{\circ}$.

The calculations of solar potential under urban conditions was carried out by the example of Volzhskiy of Volgograd area. 
Volzhskiy of Volgograd region, like most settlements of the Lower Volga region, has a high solar energy potential: $1228.8 \mathrm{kWh} / \mathrm{m}^{2}$ per horizontal surface of power plants, which can be increased by $16.2 \%$ at its optimal orientation relatively horizon and to sides of the world. However, the expansion of the utilization of the solar energy potential of the district may be limited by the location of existing structures of buildings and structures in the urban environment.

Thus, the energy flux reaches its maximum value at the South-East or South-West orientation at the inclination angle with respect to the horizon of $50^{\circ}$. When the value of tilt angle is below $50^{\circ}$, the most favorable orientation is southern one. However, when the solar power station is installed on the building roof, the orientation of solar modules to the sides of the world corresponds to the orientation of the roof slope. Analysis of the values of the tilt angles relatively the horizon with such structural constraint revealed that when orientation of solar module is eastern or western, as well as the southeastern or southwestern, large values of the inclination angles relatively horizon have to be chosen, as this spatial position is aimed at the utilization of solar radiation at the dawn and sunset times when the Sun is low above the horizon.

It can be also noted that the maximum and minimum values of the total radiation were detected for the southern orientation, respectively, at $20^{\circ}$ and $50^{\circ}$ relatively the horizon. So, at the eastern orientation, the radiation intensity decreases with an increase in the inclination angle of the receiving platform from $499.6 \mathrm{kWh} / \mathrm{m}^{2}$ to $489.1 \mathrm{kWh} / \mathrm{m}^{2}$.

\section{References}

[1] Antonio Urbina, «Solar electricity in a changing environment: The case of Spain», Renewable Energy, No. 68, pp. 264-269, 2014.
[2] M. Tripathy, P.K. Sadhu, S.K. Panda, «A critical review on building integrated photovoltaic products and their applications», Renewable and Sustainable Energy Reviews, vol. 61, pp. 451-465, 2016.

[3] C.-J. Winter, Solar Power Plants, Springer - Verlag, Berlin, Heidelberg 1991.

[4] Yu.V.Daus, I.V. Yudaev, «Designing of Software for Determining Optimal Tilt Angle of Photovoltaic Panels», Proceedings of International Conference on Education, Management and Applied Social Science (EMASS2016), pp. 306-309, November 2016 [2016 International Conference on Education, Management and Applied Social Science (EMASS2016), p. 522, 2016]

[5] Jee Joe Michael, Iniyan Selvarasan, «Economic analysis and environmental impact of flat plate roof mounted solar energy systems», Solar Energy, No. 142, pp.159-170, 2017.

[6] A. Martinez-Rubio, F. Sanz-Adan, J. Santamaria, «Optimal design of photovoltaic energy collectors with mutual shading for pre-existing building roofs», Renewable Energy, vol.78, pp. 666-678, 2015

[7] Hamid Moghadam, Saeed Moghadam Deymeh, «Determination of optimum location and tilt angle of solar collector on the roof of buildings with regard to shadow of adjacent neighbors», Sustainable Cities and Society, vol. 14, pp. 215-222, 2015.

[8] M. Libra, V. Beránek, J. Sedlác`ek, V. Poulek, I.I. Tyukhov, «Roof photovoltaic power plant operation during the solar eclipse», Solar Energy, No. 140, pp. 109-112, 2016.

[9] Yu. V. Daus, V. V. Kharchenko, and I. V. Yudaev, «Evaluation of Solar Radiation Intensity for the Territory of the Southern Federal District of Russia when Designing Microgrids Based on Renewable Energy Sources», Applied Solar Energy, vol. 52, No. 2, pp. 124-129, 2016.

[10] Bidur Raj Gautam, Fengting Li, Guo Ru, «Assessment of urban roof top solar photovoltaic potential to solve power shortage problem in Nepal», Energy and Buildings, vol. 86, pp. 735-744, 2015.

[11] Ísis Portolan dos Santos, Ricardo Rüther, «Limitations in solar module azimuth and tilt angles in building integrated photovoltaics at low latitude tropical sites in Brazil», Renewable Energy, vol. 63, pp. 116124,2014

[12] Lee Xia Sheng [et al.], «Integrated Sustainable Roof Design», Procedia Engineering, vol. 21, pp. 846-852, 2011. 